\title{
Perfil do uso populacional de inseticidas domésticos no combate a mosquitos
}

\section{Profile of the population use of household insecticides against mosquitoes}

\author{
Luzilene Barbosa de Oliveira ${ }^{1}$; Rafaela Maria Pessoa Nunes²; Claudiana \\ Mangabeira Santana ${ }^{3}$; Antônia Rosa da Costa ${ }^{4}$; Narcia Mariana Fonseca Nunes ${ }^{5}$; \\ Iana Bantim Felicio Calou ${ }^{6}$; Ana Paula Peron ${ }^{7}$; Marcia Maria Mendes Marques ${ }^{8}$; \\ Paulo Michel Pinheiro Ferreira ${ }^{9}$
}

\begin{abstract}
Resumo
Esse trabalho descreve a utilização doméstica de inseticidas pela população de Picos (Piauí, Brasil), identifica quais são os tipos de inseticidas mais utilizados e descreve a incidência de intoxicação e a consciência ambiental da população. Após visitas domiciliares $(n=700)$, notou-se que a maioria dos entrevistados foi representada por mulheres (75\%), com idade entre $31-55$ anos $(49 \%)$, ensino fundamental incompleto $(38,1 \%)$ e renda familiar entre 1-2 salários mínimos (64\%). A maioria das residências tem entre 1-3 moradores (48\%), 85\% dos entrevistados usam inseticidas escolhidos principalmente em propagandas de TV e radio e apenas $54 \%$ leem o rótulo antes de aplicar o produto. A forma de apresentação mais usada é o aerossol (70,7\%). A maioria (79\%) reconhece que inseticidas são maléficos à saúde, mas $74 \%$ não usam nenhum Equipamento de Proteção Individual (EPI). Sintomas de toxicidade foram relatados por 27\% dos entrevistados. Duas mulheres relataram irritação, tonturas e problemas respiratórios e necessidade de intervenção médica e internação hospitalar. Todos os entrevistados descartam as embalagens como lixo comum, uma vez que em Picos não há coleta seletiva. Em conclusão, a maioria das pessoas usam inseticidas, conhecem sobre os riscos individuais e coletivos aos quais estão expostos mas não usam EPI mesmo acreditando que sejam tóxicos. Notou-se que aquisição de conhecimentos não resulta, necessariamente, em mudanças de comportamento, uma vez que o conhecimento não se traduz em atitudes e práticas preventivas adequadas, ressaltando-se a necessidade de campanhas de conscientização quanto à toxicidade e aos riscos ambientais, capacitação de profissionais e política fiscalizatória contra a venda indiscriminada.
\end{abstract}

Palavras-chave: Agrotóxicos domésticos. Práticas preventivas. Piretróides. Toxicidade.

${ }^{1}$ Graduada em Ciências Biológicas, Universidade Federal do Piauí, Teresina, Piauí, Brasil. E-mail: lonlita@hotmail.com.

${ }^{2}$ Graduada em Ciências Biológicas, Universidade Federal do Piauí, Teresina, Piauí, Brasil. E-mail: rafaella-teen@hotmail.com.

${ }^{3}$ Graduada em Ciências Biológicas, Universidade Federal do Piauí, Teresina, Piauí, Brasil. E-mail: claudianasantana_22@hotmail. com.

${ }^{4}$ Graduada em Ciências Biológicas, Universidade Federal do Piauí, Teresina, Piauí, Brasil. E-mail: rosacosta100@hotmail.com.

${ }^{5}$ Graduada em Ciências Biológicas, Universidade Federal do Piauí, Teresina, Piauí, Brasil. E-mail: aicran@hotmail.com.

${ }^{6}$ Doutora e docente do Departamento de Nutrição, Universidade Federal do Piauí, Teresina, Piauí, Brasil. E-mail: ianacalou@ gmail.com.

${ }^{7}$ Doutora e docente do Departamento de Ciências Biológicas / Programa de Pós-Graduação em Genética e Melhoramento, Universidade Federal do Piauí, Teresina, Piauí, Brasil. E-mail: anpapegenpes@hotmail.com.

${ }^{8}$ Doutora e docente do Departamento de Ciências Biológicas, Universidade Federal do Piauí, Teresina, Piauí, Brasil. E-mail: anpapegenpes@hotmail.com; marciammm2003@gmail.com

${ }^{9}$ Doutor e docente do Departamento de Biofísica e Fisiologia, Laboratório de Cancerologia Experimental, Universidade Federal do Piauí, Teresina, Piauí, Brasil. E-mail: pmpf@ufpi.edu.br (contato para correspondência). 


\begin{abstract}
This study described the use of household insecticides in Picos (Piauí, Brazil), identify which are the most used types of insecticides and describes the incidence of poisoning and environmental awareness of the population. After home visits $(\mathrm{n}=700)$, it was seen that the majority of respondents was represented by women (75\%), with 31-55 years-old (49\%), incomplete primary education $(38.1 \%)$ and income between 1-2 earnings (64\%). Most homes have between 1-3 residents (48\%), 85\% of the persons use insecticides mainly chosen in TV and radio and only $54 \%$ of them read the label before employing the product. The most used form of presentation is the aerosol (70.7\%). Majority $(79 \%)$ recognizes that insecticides are harmful to health, but $74 \%$ do not use any Personal Protective Equipment (PPE). Symptoms of toxicity were reported by $27 \%$ of people interviewed. Two women reported irritation, dizziness and respiratory problems and need for medical intervention and hospitalization. All interviewed discard the package as regular trash, since Picos does not has selective collection. In conclusion, most people use insecticides, know about the individual and collective risks to which they are exposed but do not use PPE, though they believe insecticides are toxic. It was noted that acquisition of knowledge does not necessarily result in behavioral changes, since learning does not translate into appropriate preventive attitudes and practices, emphasizing the requirement for awareness campaigns about toxicity and environmental risks, preparation of professionals and surveillance policy against indiscriminate sale.
\end{abstract}

Keywords: Household pesticides. Preventive habits. Pyrethroids. Toxicity.

\section{Introdução}

Os insetos são transmissores de doenças que ocorrem cada vez mais em áreas periurbanas ou urbanas devido à introdução ou reaparecimento de seus respectivos vetores, como a dengue, febre amarela e malária, e são causa importante de prejuízos agrícolas (CONSOLI; OLIVEIRA, 1994; FERREIRA et al., 2009; LARA; BATISTA, 1992). As estratégias de controle das doenças transmissíveis por vetores biológicos são de difícil execução, principalmente quando associados à existência de reservatórios domésticos e silvestres e aos aspectos ambientais (MACIEL et al., 2010). De todas as formas de controle conhecidas, o controle químico com inseticidas de origem orgânica é uma das metodologias mais adotadas como parte do manejo sustentável e integradas para o controle de vetores em Saúde Pública (BRAGA; VALLE, 2007).

Os países em desenvolvimento são responsáveis por $20 \%$ do mercado mundial de agrotóxicos. O Brasil desponta como o maior consumidor de agrotóxicos da América Latina e o oitavo maior consumidor de agrotóxicos por hectare no mundo, respondendo por $50 \%$ da quantidade comercializada, sendo os herbicidas e os inseticidas responsáveis por $60 \%$ dos produtos comercializados no país (CAVALARI, CAMPESATTO, 2007; KÖRBES et al., 2010).

O uso crescente de inseticidas em residências tem sido atribuído a infestações por insetos hematófagos, como o Aedes aegypti, Aedes albopictus, Culex sp., Lutzomyia sp., Anopheles sp., Triatoma sp., além de formigas e cupins (CONSOLI; OLIVEIRA, 1994; SANTOS et al., 2007). Tradicionalmente, a principal estratégia para o controle do Aedes aegypti tem sido o uso intensivo de inseticidas para a eliminação do mosquito ou de suas larvas (FERREIRA et al., 2009).

O uso de inseticidas domésticos tornou-se tão comum nos domicílios urbanos que a proteção mecânica, como mosquiteiros e telas, ficou esquecida (DIEL; FACCHINI; DALL'AGNOL, 2003). Várias marcas comerciais de inseticidas e formas de apresentações diferentes com princípios ativos e similares aparecem nas prateleiras dos supermercados e pontos de venda. O consumidor, que na maioria das vezes, desconhece as propriedades tóxicas dos componentes dessas formulações (princípios ativos e adjuvantes como, solventes, propelentes e sinérgicos) é atraído pela mídia, a qual oferece esses produtos como se fossem inócuos (INFANTE-RIVARD et al., 
1999). O risco de intoxicação torna-se elevado uma vez que a população em geral faz uso de inseticidas frequentemente sem respeitar as normas básicas de segurança e por causa da livre comercialização que levam ao agravamento nos quadros de contaminação humana e ambiental (DIEL; FACCHINI; DALL'AGNOL, 2003; MIRANDA et al., 2007).

Por orientação da Agência Nacional de Vigilância Sanitária (ANVISA), as campanhas de combate aos vetores transmissores da doença de Chagas e dengue e febre amarelautilizam organofosforados e piretróides. Em campanhas passadas, foram utilizados compostos organoclorados aromáticos e linfáticos, assim como nos últimos anos, o malathion e cipermetrina têm sido utilizados no controle de vetores. O malathion é um organofosforado reconhecidamente tóxico para seres humanos e carcinogênicos para animais. Essa situação caracteriza uma condição de risco de exposição múltipla dos agentes de saúde que atuam nesses programas e campanhas, aplicando esses produtos no ambiente e nos domicílios (TEIXEIRA; AUGUSTO; MORATA, 2003). Com a entrada em vigor da Lei ${ }^{0} 7.802$, de 11 de julho de 1989, os produtos contendo substâncias carcinogênicas, teratogênicas ou mutagênicas passaram a ter registros proibidos (ANVISA, 2015).

Contrastando com a realidade, há uma grande escassez de estudos sobre o uso de inseticidas domésticos. A literatura existente relacionase predominantemente ao uso ocupacional dos inseticidas, esses estudos têm mostrado graves danos à saúde decorrente do uso intensivo e continuado desses produtos, muitas vezes sem os necessários recursos de proteção (DIEL; FACCHINI; DALL'AGNOL, 2003).

Conhecida como a cidade do alho, da cebola e da comercialização da castanha, hoje Picos é uma cidade piauiense nacionalmente apelidada de "Capital do Mel". Durante décadas, o município de Picos tem sido o segundo maior pólo de arrecadação de Impostos Sobre Circulação de Mercadorias e Serviços (ICMS) para o governo estadual e exerce grande influência socioeconômica na região centrosul do Piauí e nos estados vizinhos do Ceará e Maranhão (LUZ et al., 2014; PICOS, 2015), graças ao vertiginoso crescimento econômico, o que tem atraído pessoas de quase todas as regiões brasileiras. Assim, esse trabalho analisou o perfil da utilização doméstica de inseticidas pela população da cidade de Picos, identificou quais são os tipos de inseticidas mais utilizados e descreve a incidência de intoxicação causada pelo uso de inseticidas e a consciência ambiental dessa população.

\section{Materiais e Métodos}

A pesquisa foi realizada na cidade Picos, Estado do Piauí, entre os meses de março e julho de 2012 por meio de entrevista com aplicação de um questionário a 700 indivíduos com idade entre 18 e 90 anos nos seguintes bairros de Picos: Junco, Parque de Exposição, Pantanal, Bomba, Canto da Várzea, Pedrinhas, Centro e Samambaia. A visita foi feita em casas alternadas nas principais ruas de cada bairro. Após duas tentativas de entrevista sem sucesso, a visita à residência foi excluída. Dentro da cada bairro, o número de domicílios investigados foi proporcional à população, de acordo com os dados disponibilizados pela Prefeitura da cidade de Picos. O questionário foi composto de dezessete perguntas de múltipla escolha a fim de obter principalmente as seguintes informações: sexo, idade, estado civil, renda familiar, inseticidas mais usados, uso de equipamentos de proteção, toxicidade e consciência ambiental. Não houve identificação nominal nem risco moral para os participantes. Os participantes responderam o questionário de forma individual, sem qualquer tipo de consulta e sem interferência do pesquisador nem se fazia necessário entrar na casa do entrevistado para a aplicação do questionário. Um Termo de Consentimento Livre e Esclarecido (TCLE) foi aplicado após o aceite de aplicação do questionário. Esta pesquisa seguiu as normas estabelecidas pela Declaração de Helsinque (1975), está de acordo com a Resolução 466/2012 
do Conselho Nacional de Saúde e foi aprovada pelo Comitê de Ética em Pesquisa da Universidade Federal do Piauí (CAAE - 0409.0.045.000-11). Os resultados foram expressos em valores reais ou percentuais utilizando o programa Excel (Windows 2010).

\section{Resultados e Discussão}

O desenvolvimento de inseticidas que permanecem ativos por longos períodos foi um dos mais importantes avanços no controle de artrópodes no século $\mathrm{XX}$, principalmente no controle de insetos vetores de doenças no meio urbano (FARIA; FASSA; FACCHINI, 2007). O uso continuado ou intermitente durante quase 6 décadas de milhares de toneladas de inseticidas acarretou problemas decorrentes do seu modo de ação não seletivo, ao eliminar organismos não alvo, tanto invertebrados quanto vertebrados, causando impacto ambiental e desequilíbrio nos ecossistemas (MELO et al., 2008). A Organização Mundial de Saúde (OMS) estima que ocorram aproximadamente três milhões de envenenamentos humanos por pesticidas em todo o mundo ao longo de um ano, com relatos de mais de 220.000 mortes (KORBES et al., 2010). No entanto, são poucos os estudos existentes sobre o uso desses produtos em ambientes domésticos (MELO et al., 2008; OLIVEIRA; BURIOLA, 2009).

$\mathrm{Na}$ presente pesquisa realizada com visitas domiciliares, foram entrevistados 700 indivíduos, dos quais a maioria foi representada por mulheres (527 entrevistas, 75\%). A maior proporção de mulheres pode ser explicada pela ausência dos homens no domicílio no horário em que as entrevistas foram realizadas (quase sempre das 8 às 16h) já que a maioria das mulheres realiza somente trabalhos domésticos, não se distanciando de casa por um tempo muito prolongado (JACOBY et al., 2002; NUNES; DANTAS; FERREIRA, 2012).

No estudo, de um modo geral, predominou o baixo nível de escolaridade, com a maioria dos entrevistados apresentando apenas o ensino fundamental incompleto $(38,1 \%)$ e apenas $19 \%$ disseram ter concluído o segundo grau. Os analfabetos representaram um percentual bem expressivo do total, chegando a 12\% (Figura 1). Rangel, Rosa e Sarcinelli (2011) mostrou que a maioria dos entrevistados $(52,5 \%)$ frequentaram a escola por, no máximo quatro anos, ou seja, a grande maioria não possui ensino fundamental completo.

Figura 1 - Perfil de escolaridade dos entrevistados da cidade de Picos, Piauí (n=700).

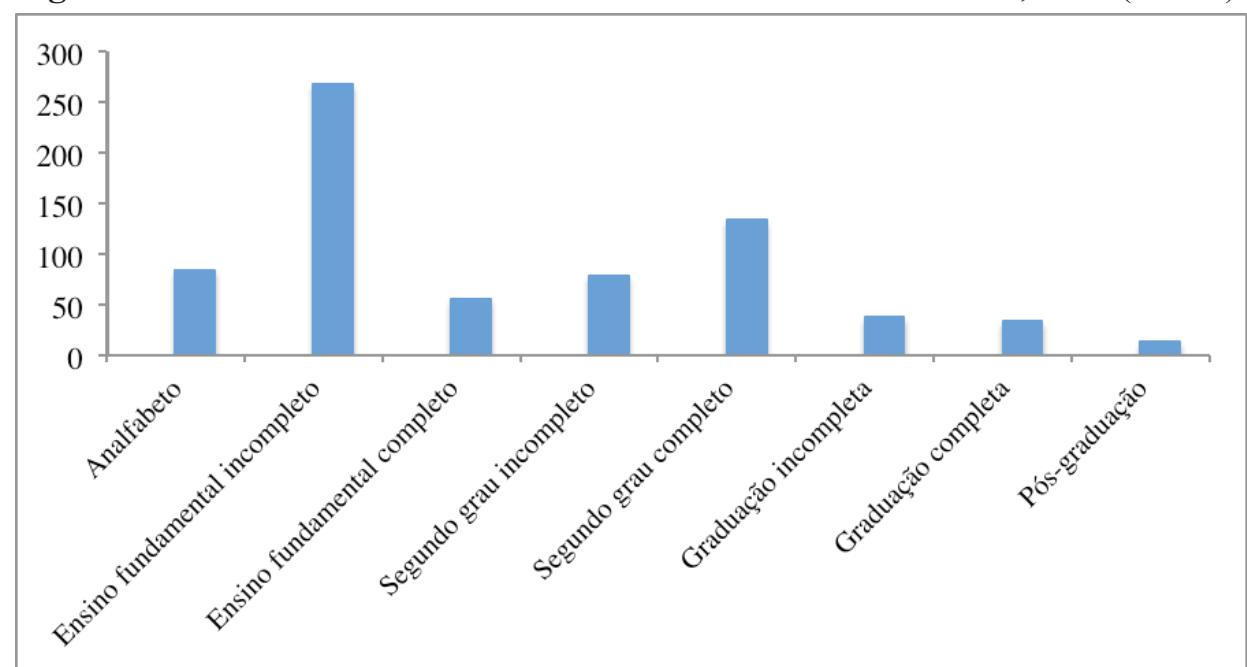

Fonte: Autores. 
A faixa etária predominante dos entrevistados ficou entre 31-55 anos de idade (341 pessoas, 49\%), enquanto $28 \%$ deles estavam na faixa entre $15-30$ anos, $13 \%$ entre $61-75$ anos, $7 \%$ entre $56-60$ anos e apenas 3\% com idade superior a 76 anos (Figura 2). Resultados similares foram encontrados em Rangel et al., (2011) onde as idades variaram de 16 a 65 anos, sendo que a maioria (52,5\%) encontrava-se na faixa etária entre 25 a 50 anos, $27,5 \%$ tinha idade menor que 25 anos e $20 \%$ maior que 50 anos. Já em Faria, Fassa e Facchini (2009), a média de idade dos trabalhadores rurais que relataram fazer uso de agrotóxicos com propriedades inseticidas foi de 38,5 anos de idade, variando entre 16 e 71 anos.

Figura 2 - Faixa etária dos entrevistados da cidade de Picos, Piauí (n=700). Valores em percentagem.

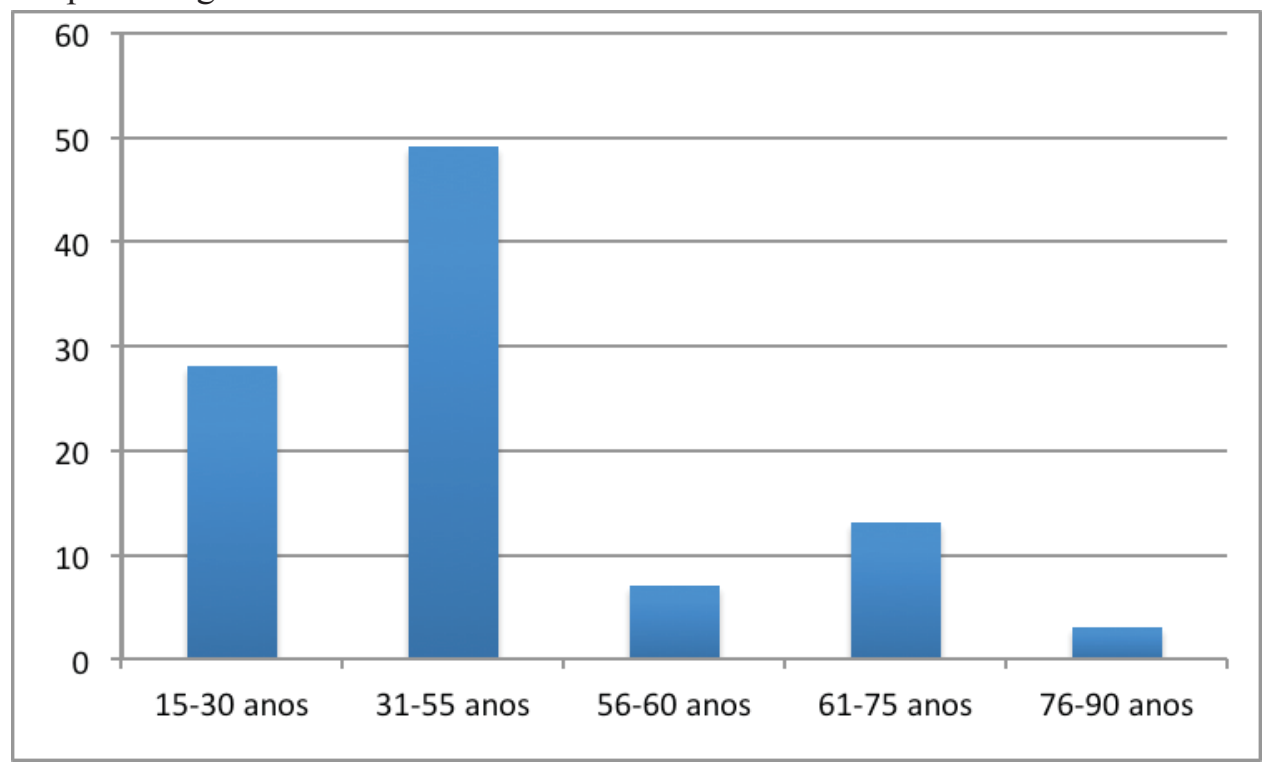

Fonte: Autores.

No que diz respeito à situação financeira das famílias entrevistadas, a maioria informou possuir renda média familiar em torno de um e dois salários mínimos mensais $(84,14 \%, 589$ pessoas), 14,42\% (101) possuíam ate cinco salários e apenas 1,2\% ( 9 pessoas) disseram possuir entre 5 a 10 salários, sendo, portanto, a maioria pertencente à classe $\mathrm{D}$, de acordo com a divisão de classes baseada na renda descrita pela Fundação Getúlio Vargas (NÉRI, 2013). Ao avaliar o perfil socioeconômico de 2.039 domicílios da área urbana de Pelotas (Rio Grande do Sul) sobre uso de inseticidas domésticos, Diel, Facchini e Dall Agnoll (2003) revelaram que $2 / 3$ da amostra apresentaram renda mensal de até 2 salários mínimos. Já Rangel, Rosa e Sarcinelli (2011) mostraram que $67,7 \%$ do total de entrevistados possuíam renda de até 2 salários mínimos e $17 \%$ mais de dois salários mínimos. É importante destacar que a pesquisa do presente trabalho foi realizada em bairros com diferentes níveis socioeconômicos. Nos bairros considerados mais abastados do ponto de vista econômico, houve certa resistência por parte dos moradores em responder o questionamento sobre renda mensal. Além do fato de que alguns não abriam suas portas para responderem o questionário. Estes vieses certamente interferiram no resultado final dos dados e seriam responsáveis pelo alto percentual de pessoas considerada pertencente à classe $\mathrm{D}$.

A maioria das residências possuía entre $1 \mathrm{e}$ 3 moradores por domicílio (48\%), 46,5\% (326) 
possuía entre 4 a 6 moradores, $4 \%$ com 7 a 9 pessoas e apenas $0,71 \%$ de 10 a 15 pessoas (Tabela 1 ).

Quando analisado por bairros, o Canto da Várzea foi que apresentou um maior percentual de residências com 4-6 moradores, enquanto os bairros Bomba e Exposição apresentaram cada um 8 residências com até 8 pessoas. Resultados obtidos por Diel, Facchini e Dall'Agnol (2003) revelaram que a média de pessoas por domicílio ficou em torno de 3 pessoas.

Tabela 1 - Número de pessoas por residência na cidade de Picos, Piauí.

\begin{tabular}{cccccccccc}
\hline \multirow{2}{*}{ Moradores por domicílio } & \multicolumn{1}{c}{ Bairros $^{*}$} & \multicolumn{2}{c}{ Total } \\
\cline { 2 - 9 } & I & II & III & IV & V & VI & VII & $(\%)$ \\
\hline 1 a 3 & 59 & 46 & 31 & 56 & 55 & 47 & 48 & $342(48,42)$ \\
4 a 6 & 37 & 49 & 67 & 42 & 37 & 44 & 50 & $326(46,57)$ \\
7 a 9 & 4 & 4 & 1 & 1 & 8 & 8 & 2 & $28(4)$ \\
10 a 15 & - & 1 & 1 & 1 & - & 1 & 1 & $5(0,71)$ \\
\hline
\end{tabular}

* I - Junco; II - Pedrinhas; III - Canto da Várzea; IV - Centro; V - Bomba; VI - Exposição; VII - Samambaia.

Fonte: Autores.

Quanto ao uso de inseticidas, 85\% (597) responderam que usam ou já usaram nos domicílios por causa da grande incidência de insetos e das más condições de saneamento e 15\% (103) relataram não usar nenhum tipo de inseticida na residência por ter conhecimento dos malefícios ou por medo da ação do produto. Apesar da maioria dos entrevistados serem do sexo feminino, várias vezes foram enfatizadas que são os homens quem aplicam os inseticidas no local. Interessantemente, embora 15\% tenha afirmado não usar inseticidas, a maioria, ao longo da entrevista, afirmou usar repelente para pele. Os dados encontrados no presente trabalho foram confirmados por Diel, Facchini e Dall'Agnol (2003), que relatam o uso de inseticidas em $89 \%$ dos domicílios visitados.

A alta prevalência de uso de inseticidas está correlacionada com vários fatores como clima, relevo, solo e condições de saneamento básico da cidade e de certa forma, ao desconhecimento das propriedades tóxicas desses produtos, aos quais ficam expostos, deixando de lado as proteções mecânicas como mosqueteiros e uso de telas (DIEL; FACCHINI; DALL'AGNOL, 2003). Segundo a Associação Brasileira das Indústrias de
Produtos de Limpeza e Afins (ABLIPA, 2013), as vendas de inseticidas no Brasil e no mundo crescem proporcionalmente à elevação da temperatura, e nas regiões mais quentes este crescimento está relacionado ao surgimento de casos de doenças provocadas por insetos, em especial a dengue.

Quando questionados sobre o local onde foram obtidas informações para a compra do produto, verificou-se que a maioria dos entrevistados se deixa levar por propagandas de TV e radio (246 citações) e por indicação de parentes e vizinhos (114) ou compra o produto quando se dirige ao supermercado e escolhe por conta própria de acordo com o tipo de inseto que deseja eliminar ou por determinadas marcas que tem prestigio no mercado (Figura 3). De fato, a televisão tem sido o principal meio de comunicação usado pelas grandes empresas de inseticidas para a divulgação em massa de seus produtos (ABIPLA, 2013).

$\mathrm{O}$ achado que chamou mais atenção foi o fato de que uma minoria obtêm informações em escolas e universidades (7 citações), embora a procura da orientação de algum profissional de saúde (107) tem sido mais lembrada. É importante enfatizar que foi considerado como profissional 
de saúde pelos entrevistados os agentes de saúde e os agentes de controle de endemias, aos quais entrevistados afirmam que costumeiramente perguntam quais os melhores inseticidas para determinada praga. Diferentemente, no trabalho de Castro e Confalonieri (2005) observou-se que $40 \%$ dos agricultores utilizavam agrotóxicos com propriedades inseticidas quando indicados por um agrônomo, $15 \%$ pelo vendedor da loja e somente $12,5 \%$ procuravam sugestão de parentes, amigos e/ou vizinhos que já tivessem usado o produto.

Figura 3 - Local onde os entrevistados obtém informação sobre inseticidas na cidade de Picos, Piauí (n=700).

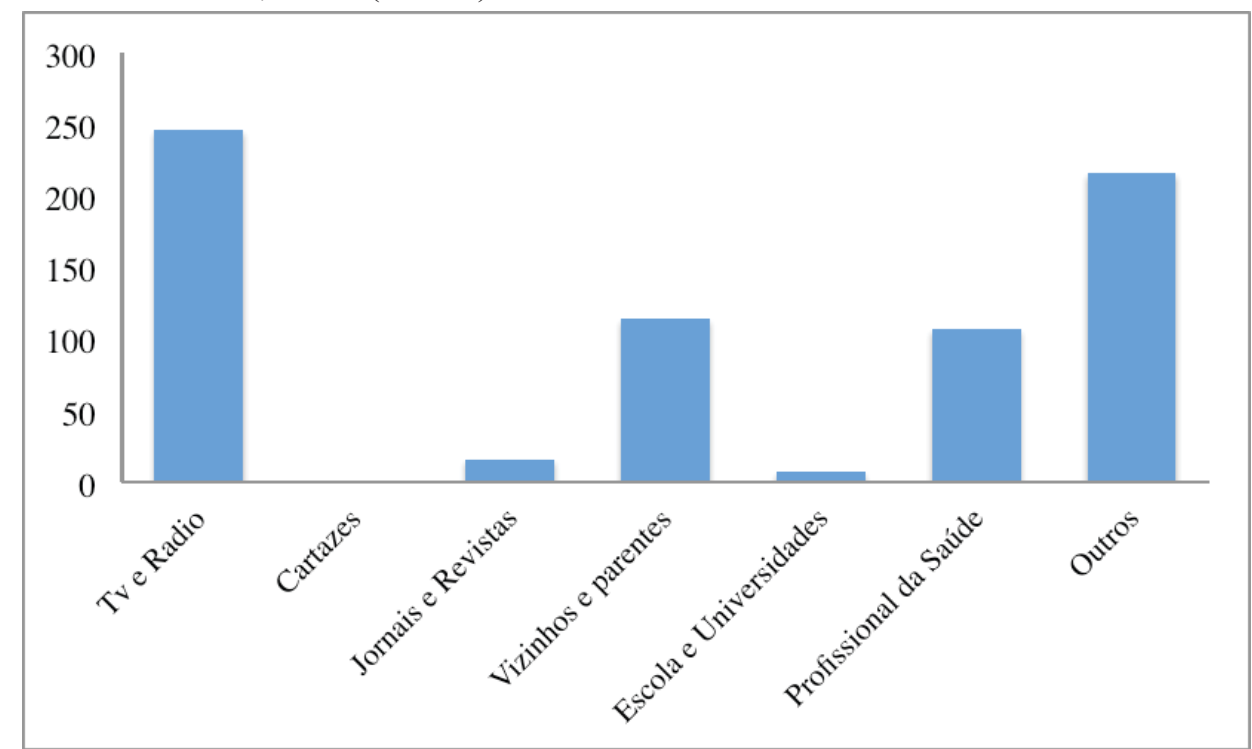

Fonte: Autores.

Dos entrevistados que afirmaram usar inseticidas, 54\% (323) disseram ler o rótulo antes de aplicar o produto, enquanto 46\% (274) admitiram não ler nada antes do uso por entenderem que já sabem a maneira correta de utilização. Dados semelhantes foram descritos por Rangel, Rosa e Sarcinelli (2011), relatando que 52,5\% dos entrevistados nunca leram os rótulos das embalagens, sendo a principal limitação a utilização de termos técnicos, a falta de clareza nas informações e uso de letras pequenas que dificultam a leitura (WAICHMAN; EVE; NINA, 2006). Por outro lado, Castro e Confalonieri (2005), em Cachoeiras de Macacu (Rio de Janeiro), observaram que $52,5 \%$ dos entrevistados liam os rótulos dos pesticidas antes do uso. Coutinho (1994), em um estudo realizado no município de Paty do Alferes (Rio de Janeiro), já alerta para o fato de que a leitura dos rótulos e a compreensão dos procedimentos de preparação e utilização de agrotóxicos seriam condições indispensáveis para o manejo e aplicação do produtos de forma adequada, diminuindo os possíveis danos à saúde e ao meio ambiente decorrentes de seu uso.

É importante enfatizar que trabalhos tem sugerido que o nível educacional não seria o motivo da não leitura dos rótulos, uma vez que até mesmo os agricultores com mais anos de estudo não liam o rótulo dos produtos antes do uso, achado preocupante já que a leitura do rótulo é uma condição imprescindível para boas práticas de segurança (WAICHMAN; EVE; NINA, 2006).

As formas de apresentação dos inseticidas mais utilizados nos domicílios visitados foram os 
aerossóis (70,7\%, 495 citações), seguidos pela solução pulverizadora $(8,1 \%)$, repelentes para pele $(4 \%)$, pastilhas $(3,5 \%)$, fumigador $(2,7 \%)$, isca $(1,7 \%)$ e espiral 1\% (7) (Figura 4). Alguns dos entrevistados usam mais de uma forma de apresentação e daqueles indivíduos que não usam inseticidas detectou-se um percentual de 8,3\%, confirmando a estimativa dos $15 \%$ que afirmaram não usar inseticidas mas que usam repelente para pele. De maneira similar, Diel, Facchini e Dall'Agnoll (2003) mostraram que as formas de apresentação mais prevalentes foram os aerossóis $(63,7 \%)$, pastilhas $(34,9 \%)$ e solução pulverizadora $(25,4 \%)$. Aerossóis e solução pulverizadora são costumeiramente os inseticidas mais requeridos pela população independente da classe social
(BRAGA; VALLE, 2007), fato confirmado pelo maior volume de vendas da categoria aerossol no ano de 2010 quanto comparado a anos anteriores (ABIPLA, 2013).

Os aerossóis geralmente tem como princípio ativo os piretróides, como cipermetrina, deltametrina, cialotrina e permetrina, os quais, atualmente, são os inseticidas mais utilizados, sendo classificados como moderadamente tóxicos para mamíferos, exigem baixas quantidades para exercerem ação efetiva conta os insetos e apresentam baixo impacto ambiental (SANTOS et al., 2007; SANTOS; AREA; REYES, 2007; VIEIRA; NEVES; QUEIROZ, 2007), características que certamente tem favorecido o aumento do consumo desta classe de pesticidas.

Figura 4 - Forma de apresentação dos inseticidas usados pela população da cidade de Picos, Piauí ( $\mathrm{n}=700)$. O entrevistado teve a liberdade de citar mais de uma forma de apresentação.

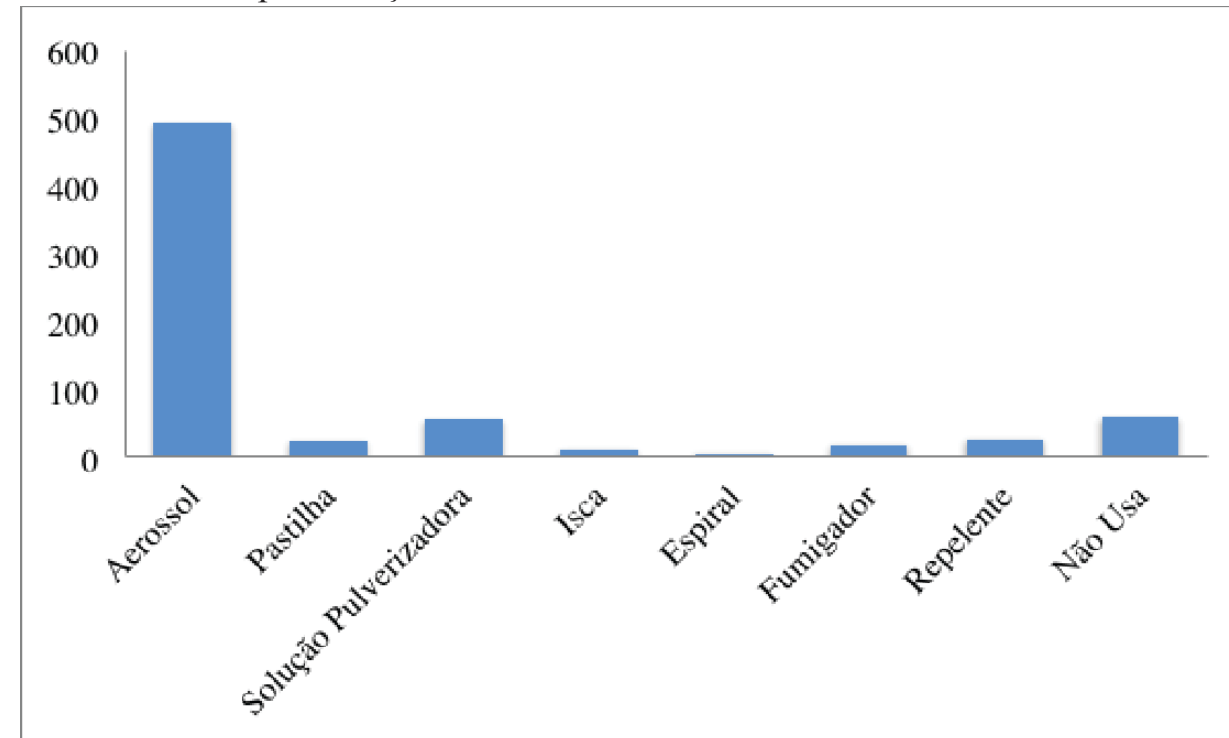

Fonte: Autores.

Ao considerar a forma de apresentação e o uso de um inseticida especifico, onde os aerossóis se destacaram, as pessoas consideraram que esse tipo tem uma ação imediata sobre os insetos $(38,7 \%)$, pela praticidade e comodidade que os aerossóis proporcionam ao consumidor $(33,7 \%)$, por indicação de outras pessoas $(4,4 \%)$ e/ou pelo simples fato de ser o mais usado (17\%). Esses achados confirmam o estudo de Diel, Facchini e Dall'Agnoll (2003), o qual demonstrou que dentre os inseticidas presentes nos 
domicílios há uma alta prevalência dos aerossóis, talvez por conta da facilidade de aplicação.

Um percentual de $79 \%$ da população reconhece que os inseticidas são maléficos à saúde, mas relatam que isso não é um impedimento para sua utilização, uma vez que consideram ser o método mais prático, mais cômodo e mais rápido contra os insetos. Enquanto isso, 21\% da população acredita que esses produtos possam ser usados sem causar nenhum dano à saúde, um achado inquietante quando se leva em consideração às informações contidas nos rótulos que alertam sobre o perigo do produto e os danos causados por eles. Previamente, um estudo que analisou o perfil socioeconômico e as práticas e costumes dos trabalhadores agrícolas de Paty do Alferes (Rio de Janeiro) revelou que a maioria dos agricultores considera os pesticidas como tóxicos (97,5\%) (RANGEL; ROSA; SARCINELLI, 2011).

O controle químico tem um papel importante nos programas de controle de endemias no Brasil, com inseticidas de origem orgânica ou inorgânica, sendo uma das metodologias mais adotadas como parte do manejo sustentável e integrado para o controle de vetores em Saúde Pública (ROZENDAAL, 1997; BRAGA; VALLE, 2007). Esse extenso uso de produtos químicos acabou sendo adotado pela população em geral como uma alternativa diária para controle de pragas nas residências. Dentre esses produtos, os piretroides produzidos em laboratório a partir de uma substância chamada piretro, são usados com conotação de atóxicos devido a sua origem natural (extraído de crisântemos). Eles são altamente eficientes para baratas e fulmigantes para as moscas e mosquitos, tem curto poder residual, são biodegradáveis, não cumulativos e raramente provocam intoxicações agudas em aves e mamíferos. Porém, eles não são isentos de toxicidade, são facilmente absorvidos pela pele e podem causar hipersensibilização e irritação na mucosa de animais (BRAGA; VALLE, 2007).

$\mathrm{Na}$ pesquisa houve um percentual significativo de entrevistados que consideram que os inseticidas não causam danos ao meio ambiente (32\%). Por outro lado, $68 \%$ acreditam que os inseticidas causam danos ao meio ambiente, basicamente porque matam insetos. Estudos prévios mostraram que a população não percebe o impacto ambiental causado por pesticidas (CASTRO; CONFALONIERI, 2005; WAICHMAN; EVE; NINA, 2006). Porém, Mota (2009) mostra que a utilização de praguicidas tem sido apontada como uns dos principais problemas para a saúde humana, ambiental e animal, devido à comprovação da presença de resíduos tóxicos em alimentos e no ambiente.

No pressente trabalho, $74 \%$ relataram não usar nenhum tipo de proteção individual durante a aplicação do produto, uma vez que a maioria que usa inseticidas em forma de aerossol o considera tão seguro que dispensa a utilização de Equipamentos de Proteção Individual (EPIs). Aqueles que não utilizam EPIs relataram que fecham as janelas e portas e saem do ambiente, inclusive retiram animais domésticos durante a aplicação do produto e, ao retornar, aguardam o arejamento do ambiente para facilitar a saída do cheiro que causa incômodo. Esse achado contradiz os resultados que relatam que $54 \%$ dos entrevistados afirmar ler os rótulos antes da aplicação do produto. Todos os rótulos indicam a utilização de alguns EPIs (como máscara e luvas) e, mesmo assim, apenas 26\% afirmaram utilizar apenas um tipo de EPI. Miranda et al. (2007), ao descrever a análise da autoproteção durante a aplicação de agrotóxicos com propriedades inseticidas, revelaram que $62,3 \%$ agricultores não utilizavam nenhum tipo de EPI. Dados semelhantes foram encontrados por Castro e Confalonieri (2005) em Cachoeira de Macacu (Rio de Janeiro), onde $82,5 \%$ dos pesquisados não utilizam EPIs durante a aplicação de defensivos agrícolas.

Dos entrevistados que relatam o uso de EPIs durante a aplicação de inseticidas, a maioria usa máscaras $(60,5 \%, 146$ citações) e luvas $(34 \%, 82)$ (Figura 5). O principal motivo que os entrevistados alegaram para usar algum tipo de proteção foi pelo fato de sentirem algum tipo de reação alérgica ou 
mal estar durante o uso prolongado de inseticidas. Mesmo assim, eles afirmaram que não deixarão de usar esses produtos, pois consideram sintomas muito leves e temporários. Essa intensa aplicação de inseticidas sem o uso adequado de EPIs podem trazer sérios riscos à saúde da população, como intoxicação, queimaduras e acidentes com crianças no caso de armazenamento inadequado. Infelizmente não existe uma politica efetiva e fiscalizatória para o controle e acompanhamento técnico adequado da utilização dos inseticidas (CAVALARI; CAMPESATTO, 2007).
Entre os entrevistados, $73 \%$ narraram nunca ter sentido nenhum tipo de sintoma ao usar inseticida. Por outro lado, 27\% relataram que durante a aplicação de inseticidas perceberam alguns sinais de intoxicação como irritação na pele e nos olhos (98), dor de cabeça (77), enjoo (45) e vertigem (25), mas outros sintomas foram discorridos durante a entrevista (Figura 6). No trabalho de Castro, Ferreira e Mattos (2011), observou-se que $23,3 \%$ dos entrevistados relataram ter sofrido intoxicação por pesticidas, sendo a irritação ou alergia, dor de cabeça, mal estar, vertigem e falta de apetite os sintomas mais citados.

Figura 5 - Tipos de Equipamentos de Proteção Individual (EPIs) usados pela população da cidade de Picos, Piauí (n=700). O entrevistado teve a liberdade de citar mais de uma forma de apresentação.

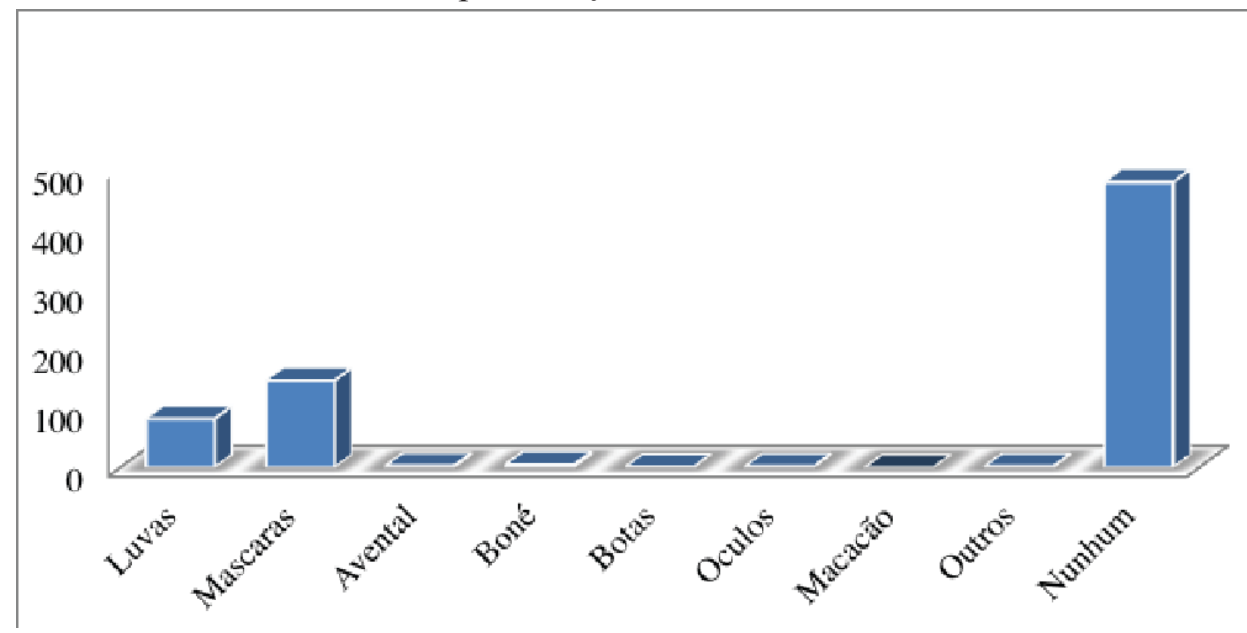

Fonte: Autores.

Figura 6 - Sintomas citados pelos entrevistados ao usar inseticidas $(n=700)$ na cidade de Picos, Piauí ( $\mathrm{n}=700$ ). O entrevistado teve a liberdade de citar mais de uma forma de apresentação.

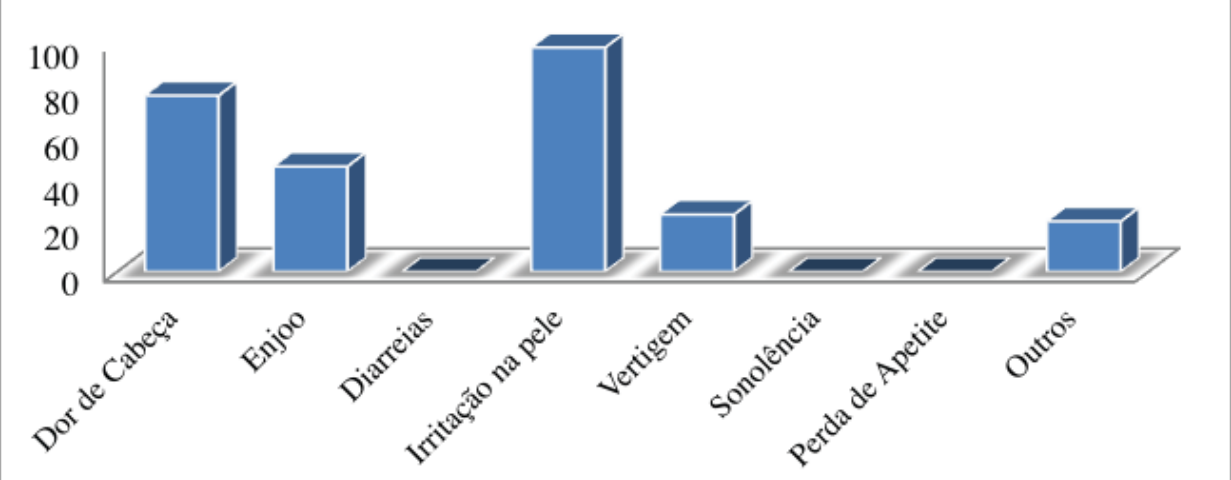

Fonte: Autores. 
Duas pessoas do sexo feminino relataram da necessidade de intervenção médica e internação hospitalar devido ao exagerado uso de inseticidas. Ambas as pessoas disseram ter sofrido de irritação, tonturas e problemas respiratórios. A pessoa que reside no bairro Pedrinhas narrou que mesmo tendo problemas de alergia não deixou de usar inseticidas devido à presença de insetos em sua residência. Porém, a partir do momento que começou a ter problemas de reação alérgica mais forte e frequentes, ela passou a usar proteção adequada e sempre sai do local após colocar o produto. A outra pessoa residente do bairro Samambaia discorreu que depois de ter passado mal com a utilização de inseticida do tipo aerossol, deixou, então, de usar qualquer produto com ação inseticida. De fato, os inseticidas líquidos são facilmente absorvidos pela pele e, tratando-se de substâncias voláteis, como os aerossóis, podem também ser absorvidas pela via respiratória e serem fatais no caso de ingestão acidental (BRAGA; VALLE, 2007).

O mecanismo de ação dos inseticidas mais usados da classe dos piretróides consiste no bloqueio de canais de sódio dos neurônios. Assim, eles afetam o sistema nervoso periférico e central do inseto ao estimularem as células nervosas a produzirem descargas repetitivas e resultante paralisia (BRAGA; VALLE, 2007). O efeito estimulante dos piretróides é muito mais pronunciado que o do DDT ${ }^{\circledR}$ (Dicloro-Difenil-Tricloroetano), um dos organoclorados mais usados no mundo contra o mosquito vetor da malária (Anopheles darlingi) e no controle de pragas da agricultura devido à características físicoquímicas vantajosas (baixa solubilidade em água, alta persistência e sua forma de ação) (FLORES et al., 2004). No entanto, a utilização desses organoclorados tem sido progressivamente restringida ou mesmo proibida. Eles atuam basicamente no SNC e no sistema de defesa do organismo e causam danos hepáticos e renais. Alguns produtos desse grupo lesam o cérebro, os miócitos cardíacos, a medula óssea e o córtex adrenal (PINHEIRO; MONTEIRO,
1992; BRUNTON; CHABNER; KNOLLMANN, 2012). Casos de câncer em órgãos do aparelho digestivo, pulmão e rins têm sido relacionados ao uso prolongado de organoclorados (OLIVEIRA; ADEODATO, 1997). Esse uso de piretroides é relativamente recente quando comparados a outras classes de compostos pesticidas (organoclorados, organofosforados e carbamatos) e muitas pesquisas não levam em consideração os efeitos de exposição a longo prazo, tais como as alterações no sistema endócrino, efeitos no SNC e o desenvolvimento de cânceres (MIRANDA et al., 2007), o que se sugere grande cautela durante seu manuseio e descarte.

O SINITOX (Sistema Nacional de Informações Tóxico-Farmacológicas) registrou em 2012 um total de 5.780 casos de intoxicação provocados por agrotóxicos em geral, correspondendo a $6,71 \%$ dos 86.028 casos notificados de intoxicações no Brasil, principalmente com mulheres. Dos 113 óbitos por agrotóxicos, $57(50,4 \%)$ casos ocorreram na região Nordeste. Estes números refletem apenas parcialmente a realidade do país, já que, segundo estimativas do Ministério da Saúde, para cada evento de intoxicação por agrotóxico notificado, existem outros cinquenta não notificados (SINITOX, 2015).

Em relação ao destino das embalagens, 84,5\% dos entrevistados discorreram que depositavam as embalagens vazias em sacolas plásticas separado do lixo comum e colocavam à disposição do sistema de coleta periódica do lixo municipal, e $14,8 \%$ colocavam as embalagens misturado com o lixo doméstico que, em seguida, também era recolhido pela coleta periódica de lixo (Tabela 2). É importante ressaltar que na cidade de Picos não há aterro sanitário nem coleta seletiva de lixo e que essas embalagens depositadas em lixões constituirá agentes de contaminação ambiental. Duas pessoas $(0,2 \%)$ disseram reutilizar as embalagens por não ter conhecimento das propriedades tóxicas dos produtos. Malacco (2005) mostrou que 90\% dos entrevistados informaram que o destino final das embalagens seria na coleta municipal de lixo, 7,5\% queimavam esse tipo de lixo e 1,3\% enterrava. 
Tabela 2 - Destino das embalagens vazias de inseticidas na cidade de Picos.

\begin{tabular}{lc}
\hline Destino de Embalagens Vazias & Total (\%) \\
\hline Lixo comum & $103(14,8)$ \\
Terrenos baldios & $4(0,5)$ \\
Coleta periódica de lixo & $591(84,5)$ \\
Reutiliza as embalagens & $2(0,2)$ \\
Coleta seletiva & - \\
\hline
\end{tabular}

Fonte: Autores.

O Brasil é único país da América Latina que possui uma legislação específica para o destino das embalagens. Segundo a Lei 7.082 de 11 de julho de 1989 e a Lei 9.974 de 6 de junho de 2000, os usuários de agrotóxicos, seus componentes e afins deverão efetuar a devolução das embalagens vazias dos produtos aos estabelecimentos comerciais em que foram adquiridos, de acordo com as instruções previstas nas bulas, no prazo de até um ano, contado da data de compra, ou prazo superior, se autorizado pelo órgão registrante (ANVISA, 2015). Segundo a ANDEF (Associação Nacional de Defesa Vegetal), a destinação final das embalagens vazias de agrotóxicos é um procedimento complexo que requer a participação efetiva de todos os agentes envolvidos na fabricação, comercialização, utilização, licenciamento, fiscalização emonitoramento das atividades relacionadas com o manuseio, transporte, armazenamento e processamento dessas embalagens. O estado do Piauí possui apenas 2 postos para a devolução de embalagens vazias (Teresina e Bom Jesus) (CHAVES, 2007). Portanto, fazemse necessários trabalhos e campanhas por parte da vigilância sanitária como forma de esclarecer a população sobre os riscos toxicológicos e ambientais do uso indiscriminado de inseticidas.

\section{Conclusão}

Os resultados mostraram que a maioria das pessoas fazem uso de inseticidas, conhecem sobre os riscos individuais e coletivos aos quais estão expostos mas usam EPIs durante a aplicação dos mesmos mesmo acreditando que inseticidas sejam tóxicos. Porém, é importante ressaltar que aquisição de conhecimentos não resulta, necessariamente, em mudanças de comportamento, uma vez que o conhecimento da população não se traduz em atitudes e práticas preventivas adequadas. Logo, esse achados apontam para a) a necessidade de campanhas de conscientização em relação aos danos que os inseticidas podem causar às pessoas, animais e ao meio ambiente como um todo; b) para a capacitação de profissionais; e c) para uma política fiscalizatória contra a venda indiscriminada destes produtos expostos nas prateleiras de supermercados.

\section{Referências}

ABIPLA - ASSOCIAÇÃO BRASILEIRA DAS INDÚSTRIAS DE PRODUTOS DE LIMPEZA E AFINS. Mercado de inseticidas cresce na guerra contra as pragas urbanas. Disponível em: <http:/ www.abre.org.br/noticias/mercado-de-inseticidascresce-na-guerra-contra-as-pragas-urbanas $/>$. Acesso em: 14 fev. 2013.

ANVISA-AGÊNCIANACIONALDEVIGILÂNCIA SANITÁRIA. Lei $n^{\circ}$ 7.802, de 11 de julho de 1989; Lei 9.974 de 6 de junho de 2000. Disponível em: <http:// portal.anvisa.gov.br/>. Acesso em: 4 fev. 2015.

BRAGA, I. A.; VALLE, D. Aedes aegypti: inseticidas, mecanismos de ação e resistência. Epidemiologia $e$ Serviços de Saúde, Brasília, v. 16, p. 279-293, 2007.

BRUNTON, L. L.; CHABNER, B. A.; KNOLLMANN, B. C. As bases farmacológicas da terapêutica. São Paulo: McGraw Hill, 2012. 
CASTRO, J. S. M.; CONFALONIERI, U. Uso de agrotóxicos no Município de Cachoeiras de Macacu (RJ). Ciências \& Saúde Coletiva, Rio de Janeiro, v. 10, p. 473-482, 2005.

CASTRO, M. G. G. M.; FERREIRA, A. P.; MATTOS, I. N. Uso de agrotóxicos em assentamentos de reforma agraria no Município de Russas (Ceará, Brasil): um estudo de caso. Epidemiologia e Serviços de Saúde, Brasília, v. 20, p. 245-254, 2011.

CAVAlARI, A. C. R.; CAMPESATTO, E. A. M. Intoxicação ocupacional por organofosforado: a importância da dosagem de colinesterase. CESUMAR, Maringá, v. 9, p. 125-134, 2007.

CHAVES, T. V. S. Avaliação do impacto do uso de agrotóxicos nos trabalhadores rurais dos Municípios de Ribeiro Gonçalves, Baixa Grande do Ribeiro e Uruçuí - Piauí. 2007. 195 f. Dissertação (Mestrado em Farmacologia) - Universidade Federal do Ceará, Fortaleza.

CONSOLI, R. A. G. B.; OLIVEIRA, R. L. Principais mosquitos de importância sanitária no Brasil. Rio de Janeiro: Fiocruz, 1994.

COUTINHO, J. A. G. Uso de agrotóxicos no Município de Paty do Alferes: um estudo de caso. Cadernos de Geociências, Salvador, v. 10, p. 23-31, 1994.

DIEL, C.; FACCHINI, L. A.; DALL'AGNOL, M. M. Inseticidas domésticos: padrão de uso segundo a renda per capita. Revista de Saúde Pública, São Paulo, v. 37, p. 83-90, 2003.

FARIA, N. M. X.; FASSA, A. G.; FACCHINI, L. A. Intoxicação por agrotóxicos entre trabalhadores rurais de fruticultura, Bento Gonçalves, RS. Revista de Saúde Pública, São Paulo, v. 43, p. 335-344, 2009.

. Intoxicação por agrotóxicos no Brasil: os sistemas oficiais de informação e desafios para realização de estudos epidemiológicos. Ciências \& Saúde Coletiva, Rio de Janeiro, v. 12, p. 25-38, 2007.
FERREIRA, P. M. P.; CARVALHO, A. F. F. U.; FARIAS, D. F.; CARIOLANO, N. G.; MELO, V. M. M.; QUEIROZ, M. G. R.; MARTINS, A. M. C.; MACHADO-NETO, J. G. Larvicidal activity of the water extract of Moringa oleifera seeds against Aedes aegypti and its toxicity upon laboratory animals. Anais $d a$ Academia Brasileira de Ciências, Rio de Janeiro, v. 81, p. 207-216, 2009.

FLORES, A. V.; RIBEIRO, J. N.; NEVES, A. A.; QUEIROZ, E. L. R. Organoclorados: um problema de saúde pública. Ambiente \& Sociedade, São Paulo, v. 7, p. 111-125, 2004.

INFANTE-RIVARD, C.; LABUDA, D.; KRAJINOVIC, M.; SINNETT, D. Risk of chilhood leukemia associated with exposure to pesticides and with gene polymorphisms. Epidemiology, Hagerstown, v. 10, p. 481-487, 1999.

JACOBY, C.; COLTRO, E. M.; SLOMA, D. C.; MÜLLER, J.; DIAS, L. A.; LUFT, M.; BERUSKI, P. Plantas medicinais utilizadas pela comunidade rural de Guamirim, Município de Irati, PR. Revista Ciências Exatas e Naturais, Guarapuava, v. 4, p. 79-89, 2002.

KÖRBES, D.; SILVEIRA, A. F.; HYPPOLITO, M. A.; MUNARO, G. Alterações no sistema vestibulococlear decorrentes da exposição ao agrotóxico: revisão de literatura. Revista da Sociedade Brasileira de Fonoaudiologia, São Paulo, v. 15, p. 146-52, 2010.

LARA, W. H.; BATISTA, G. C., Pesticidas. Química Nova, São Paulo, v. 15, p. 161-166, 1992.

LUZ, N. N. N.; LUSTOSA, I. R.; MACHADO, K. C.; PACHECO, A. C. L.; PERON, A. P.; FERREIRA, P. M. P. Acadêmicos, a percepção sobre o papilomavírus humano e sua relação com o câncer cervical. Semina: Ciências Biológicas e da Saúde, Londrina, v. 35, p. 91$102,2014$.

MACIEL, M. V.; BEVILAQUA, C. M. L.; AMÓRA, S. S. A. Extratos vegetais usados no controle de dípteros vetores de zoonoses. Revista Brasileira de Plantas Medicinais, Botucatu, v. 12, p. 105-112, 2010.

MALACCO, M. A. F. Uso doméstico de inseticidas em residências da cidade de Lagoa Santa, Minas Gerais, Brasil. 2003. 49 f. Dissertação (Mestrado em Medicina Veterinária) - Universidade Federal de Minas Gerais, Belo Horizonte, 2005. 
MELO, M. E. B.; MERLO, K. C.; FERNANDES, R. R. C.; LUNA, C. F.; DINIZ, G. T. N.; CATANHO, M. T. J. A.; REGIS, L. Ação do inseticida organofosforado temefós em células de medula óssea de camundongos. Revista do Instituto Adolfo Lutz, São Paulo, v. 67, p. 196-201, 2008.

MIRANDA, A. C.; MOREIRA, J. C.; CARVALHO, R.; PERES, F. Neoliberalismo, uso de agrotóxicos e a crise da soberania alimentar no Brasil. Ciência \& Saúde Coletiva, Rio de Janeiro, v. 12, p. 7-14, 2007.

MOTA, M. L. Agrotóxicos e transgênicos: solução ou problema à saúde humana e ambiental? Saúde \& Ambiente em Revista, Duque de Caxias, v. 4, p. 36-46, 2009.

NÉRI, M. De volta ao país do futuro. Disponível em: $<$ http://portal.fgv.br/>. Acesso em: 19 mar. 2013.

NUNES, R. M. P.; DANTAS, S. B.; FERREIRA, P. M. P. A influencia de fatores socioeconômicos e da ação publica dos serviços de saúde no controle da dengue no município de Picos. In: REUNIÃO ANUAL DA SBPC, 64., 2012, São Luís. Anais eletrônicos... São Luís: UFMA. Disponível em: $<$ http://www.sbpcnet.org. br $\geq$. Acesso em: 20 mar. 2013.

OLIVEIRA, M. L. F.; BURIOLA, A. A. Gravidade das intoxicações por inseticidas inibidores das colinesterases no noroeste do estado do Paraná, Brasil. Revista Gaúcha de Enfermagem, Porto Alegre, v. 30, p. 648-655, 2009.

OLIVEIRA, W.; ADEODATO, S. O. O bairro que respira veneno. Globo Ciência, v. 6, p. 48-51, 1997.

PINHEIRO, A. C. F. B.; MONTEIRO, A. L. F. B. P. A. Ciências do ambiente - ecologia, poluição e impacto ambiental. São Paulo: Editora Makron, 1992.

PICOS. Prefeitura Municipal. História $e$ potencialidades: 2015. Disponível em: $<$ http://www. picos.pi.gov.br/conhecapicos.asp $>$. Acesso em: 7 fev. 2015.

RANGEL, C. F.; ROSA, A. C.; SARCINELLI, P. N. Uso de agrotóxicos e suas implicações na exposição ocupacional e contaminação ambiental. Cadernos de Saúde Coletiva, Rio de Janeiro, v. 19, p. 435-442, 2011.
ROZENDAAL, J. A. Vector control methods for use by individuals and communities. Geneva: World Health Organization, 1997.

SANTOS, M. A. T.; AREAS, M. A.; REYES, F. G. R. Piretróides: uma visão geral. Alimentos e Nutrição, Araraquara, v. 18, p. 339-349, 2007.

SANTOS, R. L. C.; FAYAL, A. S.; AGUIAR, A. E. F.; VIEIRA, D. B. R.; PÓVOA, M. M. Avaliação do efeito residual de piretróides sobre anofelinos na Amazônia brasileira. Revista de Saúde Pública, São Paulo, v. 41, p. 276-283, 2007.

SINITOX - SISTEMA NACIONAL DE INFORMAÇÕES TÓXICO-FARMACOLÓGICAS. Casos registrados de intoxicação humana por agente tóxico e circunstância. Disponível em: <http:// www. cict.fiocruz.br/intoxicacoeshumanas/ 2001/brasil2001. $\mathrm{htm}>$. Acesso em: 31 jan. 2015.

TEIXEIRA, C. F.; AUGUSTO, L. G. S.; MORATA, T. C. Saúde auditiva de trabalhadores expostos a ruído e inseticidas. Revista de Saúde Pública, São Paulo, v. 37, p. 417-423, 2003.

VIEIRA, H. P.; NEVES, A. A.; QUEIROZ, M. E. L. R. Otimização e validação da técnica de extração líquido-líquido com partição em baixa temperatura (ELL-PBT) para piretróides em água e análise por CG. Química Nova, São Paulo, v. 30, p. 535-540, 2007.

WAICHMAN, A. V.; EVE, E.; NINA, N. C. S. Do farmers understand the information displayed on pesticide product labels? A key question to reduce pesticides exposure and risk of poisoning in the Brazilian Amazon. Crop Protection, Washington, v. 26, p. 576-583, 2006.

Recebido em: 18 fev. 2015. Aceito em: 04 jun.2015. 